\section{SCIDoc Publishers}

\title{
Hot Saline Thermoablation of Peripheral Non Small Cell Lung Cancer safety and Efficacy: a Pilot Study
}

Research Article

El-Badrawy MK ${ }^{1}$, El-Shafey $\mathrm{MM}^{1}$, Hewidy $\mathrm{AA}^{1 *}$, Tohlob MA¹ Akl FM$^{2}$, Ebrahim MA³

${ }^{1}$ Chest Medicine Department, Mansoura University, Egypt.

${ }^{2}$ Clinical Oncology and Nuclear Medicine Department, Mansoura University, Egypt.

${ }^{3}$ Oncology Center, Mansoura University, Egypt.

\section{Abstract}

Hot saline thermoablation is effective and safe for hepatoma so its application to peripheral non-small cell lung cancer NSCLC may be beneficial.

Aim: Assess the efficacy and safety of palliative transthoracic hot isotonic saline injection of peripheral inoperable NSCLC Patients and Methods: Randomized clinical trial done at Chest, Clinical Oncology departments and Oncology Center Mansoura, Egypt, 2013 to 2015. 23 patients with peripheral NSCLC randomly divided to 2 groups: group A, 11 patients subjected to transthoracic hot isotonic saline injection and group B, 12 patients subjected to transthoracic injection of isotonic saline at room temperature (immediately both groups were treated with chemotherapy). Primary endpoints were clinical, functional and radiological response and tumor tissue histopathology posttreatment. Secondary endpoint was survival.

Results: Significant decrease in chest pain and dyspnea in group A versus group B, 3 and 6 months posttreatment. Hot saline braked deterioration in quality of life. After 6 months, there was statistically significant increase in FEV1 and FVC in group A versus before treatment. 8 patients in group A had partial response $72.7 \%$ and 3 patients had progression $27.3 \%$ and 7 patients in group B had stable course $58.3 \%$ and 5 patients had progression $41.7 \%$ after 6 months. 10 patients in group A had coagulative necrosis while 6 patients from group B had ischemic necrosis. There were few immediate controllable complications. Survival was better in group A than group B but statistically insignificant.

Conclusion: Hot saline thermoablation is effective, safe palliative treatment for patients with inoperable peripheral NSCLC. PACTR201601001384408.

Keywords: Thermoablation; Hot Saline; Lung Cancer.

\section{Introduction}

Lung cancer is the commonest diagnosed cancer worldwide $13 \%$ of the total) and the most common cause of cancer mortality (19.4\% of the total) [1]. Surgery carries the most favorable response but in inoperable patients, tumor debulking increases survival using multiple modalities in management of peripheral lung cancer [2].

Many ablative techniques are used for palliation of peripherally situated lung cancer as radiofrequency and microwave [3]. Percutaneous hot saline injection shows good anti-tumor effects despite a few number of punctures and gives hope as a curative local treatment method for tumors as HCC [4].

The biological and molecular mechanisms of hyperthermia are changes in cell membrane, cytoskeleton, ion-gradient and membrane potential, synthesis of macromolecules and DNA-replication, intracellular and extracellular acidosis and decrease in intracellular ATP. The induction of heat-shock proteins might intensify specific immune responses to malignant cells [5].

\section{Study Design}

Single blinded randomized clinical trial in which peripherally situated histologically diagnosed inoperable NSCLC was injected

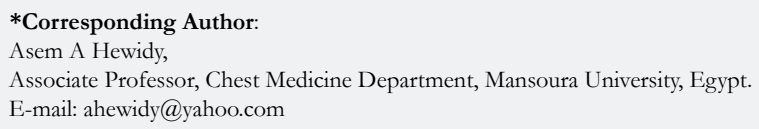

Citation: El-Badrawy MK, El-Shafey MM, Hewidy AA, Tohlob MA, Akl FM, et al., (2017) Hot Saline Thermoablation of Peripheral Non Small Cell Lung Cancer safety and Efficacy: a Pilot Study. Int J Resp Dis Care Med. 2(2), 14-21. doi: http://dx.doi.org/10.19070/2577-4409-170004 
with boiled isotonic saline in one group as palliative therapy compared to isotonic saline at room temperature in the other group. Second day after saline injection, chemotherapy was started to all patients. The primary end points of the study were injection of the total required saline volume and assessing the clinical response (symptoms score and quality of life score), functional response, radiological response and changes in tumor tissue regarding histopathology after treatment. Secondary end point was survival rate. The patients were evaluated before treatment, 3 and 6 months after treatment. Follow up was done by monthly visits during first 6 months then by phone. The patients were randomly selected using the closed envelop method.

\section{Patients and Methods}

This study was conducted at Chest Medicine Department, Clinical Oncology and Nuclear Medicine department and Oncology Center, Mansoura University Hospitals during the period from 2013 November to 2015 June. This study included 40 patients 22 males and 18 females with peripheral NSCLC of different pathological subtypes with their age range from 30 to 73 years with a mean age of $48.61 \pm 11.85$ years, only 23 patients completed the study and 17 patients were excluded (3 patients refused, 2 patients had small cell lung cancer, one patient with uncorrected bleeding profile, 8 patients received radiotherapy and 3 incompliant patients).

Ethical approval had been obtained from Medical Research Ethics Committee of Faculty of Medicine (code no: MS/353), Mansoura University and pan African clinical trial registry (number PACTR201601001384408). Patients signed their written consents after detailed explanation of the study protocol.

This study included symptomatic patients with peripherally situated NSCLC not candidate for surgery (inoperable or surgically unfit) or radiotherapy. Patients must be fit for chemotherapy with adequate bone marrow reserve as white blood cell count $>3500$ / $\mathrm{mm}^{3}$, neutrophil count $>1800 / \mathrm{mm}^{3}$, hemoglobin $>10 \mathrm{gm} / \mathrm{dL}$ and haematocrit value $>30 \%$.

Patients who were candidate for surgery, with tumors infiltrating main stem bronchi or the mediastinum, small cell lung cancer, lung metastasis, uncorrectable bleeding diathesis, uncompensated cardiac comorbidities, patients who received radiotherapy during treatment, unfit for chemotherapy and patients who refused to be included or to complete the study were excluded from the study.
The enrolled patients were randomly selected using the enclosed envelop method and divided into 2 groups according to the mode of treatment:

Group A; included 11 patients subjected to transthoracic injection of hot isotonic saline at temperature $90^{\circ}-100^{\circ} \mathrm{C}$ plus systemic chemotherapy simultaneously.

Group B; included 12 patients subjected to transthoracic injection of isotonic saline at room temperature plus systemic chemotherapy as a control group to make the hyperthermia the only variable and not saline itself or the intratumoral compression ischemic effect of the injected volume.

All patients were diagnosed by using CT- guided biopsy with $18 \mathrm{G}$ tru-cut needle and subjected to the following:

1- Clinical evaluation: Thorough medical history with stress on cough, hemoptysis, chest pain and dyspnea. These symptoms were scored before the start of treatment, 3 and 6 months after the first session of hot saline thermoablation and chemotherapy. Cough was evaluated according to Belfiore et al., (2004)[6]; no cough (0), intermittent cough (1) and persistent cough (3), hemoptysis according to Vankralingen et al., (1995) [7]; no hemoptysis(0), blood streaked (1), less than $20 \mathrm{ml} /$ day (2), $20-200 \mathrm{ml}$ / day(3) and $600 /$ day or $\geq 150 \mathrm{ml}$ in a single attack (4), chest pain scoring according to The McGill Pain Questionnaire [8]; none(0), mild, requiring no medications (1), discomforting, requiring mild analgesics (2), distressing, requiring strong analgesics (3), horrible, requiring narcotic analgesics (4) and excruciating, not responding to narcotic analgesics (5) and dyspnea according mMRC scoring of dyspnea [9]. Evaluation of quality of life status according to Gridelli et al., (2004) [10].

2- Radiological investigations: X-ray chest postero-anterior and lateral views, done on admission and after every session of chemical ablation. CT chest was done for diagnosis of peripheral lung cancer with CT guided tru-cut biopsy, staging and follow up after 3 and 6 months from the start of thermoablation.

- The radiological response to treatment was assessed according to modified response evaluation criteria in solid tumors (RECIST) (Table 1).

Pelvi-abdominal ultrasonography, CT of the abdomen, CT brain and bone scan were done for evaluation of distant metastasis be-

Table 1. Modified RECIST Criteria for Evaluation of Treatment Response [11].

\begin{tabular}{|c|c|c|}
\hline Response & CT mass size & CT mass quality \\
\hline $\begin{array}{c}\text { Complete (two of the } \\
\text { following) }\end{array}$ & $\begin{array}{c}\text { Lesion disappearance (scar) less } \\
\text { than } 25 \% \text { of original size }\end{array}$ & $\begin{array}{c}\text { Cyst or cavity formation, low } \\
\text { density entire lesion }\end{array}$ \\
\hline $\begin{array}{c}\text { Partial (one of the } \\
\text { following) }\end{array}$ & $\begin{array}{c}\text { More than } 30 \% \text { decrease in the } \\
\text { LD of target lesion }\end{array}$ & $\begin{array}{c}\text { Central necrosis or central } \\
\text { cavitation with liquid density }\end{array}$ \\
\hline $\begin{array}{c}\text { Stable lesion (one of } \\
\text { the following) }\end{array}$ & $\begin{array}{c}\text { Less than } 30 \% \text { decrease in the LD } \\
\text { of target lesion }\end{array}$ & $\begin{array}{c}\text { Mass solid appearance, no } \\
\text { central necrosis or cavitation }\end{array}$ \\
\hline $\begin{array}{c}\text { Progression (two of } \\
\text { the following) }\end{array}$ & $\begin{array}{c}\text { Increase of more than } 20 \% \text { in the } \\
\text { LD of target lesion }\end{array}$ & $\begin{array}{c}\text { Solid mass, invasion adjacent } \\
\text { structures }\end{array}$ \\
\hline
\end{tabular}

LD: largest diameter of lesion 
fore starting the study and after 6 months.

3- Fiberoptic bronchoscopy (Pentax FB 19 TV, Pentax Company Tokyo, Japan) was done for all cases once at the time of diagnosis for evaluation of the bronchial tree and staging.

4- Pulmonary function tests: Spirometry was performed at the start of the study, and after 3 and 6 month of treatment, such as forced expiratory volume in the first second (FEV1\%) of predicted, FVC and FEV1/FVC ratio were measured by spirometry (using Smart PFT CO, Medical Equipment Europe GmbH, Germany).

5- Staging was done according to 7th TNM staging system for non small cell lung cancer Goldstraw et al., [12] before the start of treatment and after 6 months.

6- Thermoablation technique: After sterilization of the skin with povidone iodine and alcohol, local anaesthesia was achieved with percutaneous infiltration of $2 \%$ lidocaine hydrochloride solution $(5-10 \mathrm{ml})$ was injected to anesthetize the skin, subcutaneous tissue, muscles, pleura and intratumoral along the track of entry. CT was used to localize the tumor, its optimal access site and the minimal depth of the needle (22 G spinal needle) inside the thoracic cage to reduce displacement from patients' breathing or motion. $\mathrm{O}_{2}$ saturation with pulse oximetry and ECG was monitored before, during and 24 hour after the procedure.

Hot saline was injected slowly over 20 minutes using a 22-gauge spinal needle with a single end bore and by varying the length and rotating the needle to achieve its wide distribution within the tumor. Hot isotonic saline at $90^{\circ}-100^{\circ} \mathrm{C}$ (boiling was done under sterile condition in water bath till desired temperature which did not dropped below $90^{\circ} \mathrm{C}$ by thermometer at the end of injection) injection by $50 \mathrm{ml}$ syringe with CT guidance and its volume was adjusted according to tumor size with maximum $100 \mathrm{ml}$ in every session. The tumor volume was considered as an irregularly shaped mass. On each section, a cross-sectional area (AP) was calculated by using the image $\mathrm{J}$ software and by using the following equation, the volume $(\mathrm{V})$ of each tumor was calculated: $\mathrm{V}=\mathrm{I}(\mathrm{AP} 1+\mathrm{AP} 2+\ldots$ APn) [13]. Saline volume was calculated according to tumor volume (every $1 \mathrm{~cm}^{3}$ was injected with $1 \mathrm{ml}$ hot isotonic saline to make thermal effect reach every part of the tumor, in group A or temperate saline in group B). The volume was injected in two to five sessions with one week interval while patients were starting chemotherapy protocol.

CT chest was done immediately after hot saline injection to detect the early complications as pneumothorax. Follow up CT chest scans were done after 3 and 6 months to evaluate the changes in the enhancement pattern (either solid mass, necrosis without cavitation or cavitation), lesion size, lymph node metastasis and delayed complications. After one week after the last session of injection, tru-cut biopsy was taken to detect histopathological changes.

7- Chemotherapy protocol: all patients were treated with cisplatin $75 \mathrm{mg} / \mathrm{m}^{2}$ on day 1 plus gemcitabine $1,250 \mathrm{mg} / \mathrm{m}^{2}$ on days 1 and 8 every 3 weeks. Cisplatin was administered on day 1 via intravenous infusion over approximately 120 minutes. Gemcitabine was administered on days 1 and 8 via intravenous infusion over approximately 30 minutes [14].
8-Follow up: The patients were followed for the first 24 hours after each session to monitor the possible complications as bleeding, hypoxemia and pneumothorax.

Clinical evaluation for the changes in patients' symptoms and quality of life.

Radiological evaluation was done by Chest X-ray P-A view and CT of the chest.

Histopathological examination of tru-cut biopsy one week after the last session of injection.

Follow up was monthly after 6 months even by phone call for survival and late complications.

9- Statistical analysis: The statistical analysis of data was done by using excel and SPSS programs statistical package for social science version 22. For quantitative data student t-test was used to compare the 2 groups. Paired sample t-test was used to compare the results before and after therapy in the same group. Chi square test was used to compare qualitative data. Correlation coefficient was done to detect association between variables. $\mathrm{P}$ is significant if $\leq 0.05$.

\section{Results}

Group A; included 11 patients ( 9 males and 2 females) with a mean age of $48.55 \pm 14.04 ; 7$ patients had adenocarcinoma, 2 patients had squamous cell carcinoma, one patient had large cell carcinoma and one patient had sarcomatoid carcinoma; one patient was stage IIb, 7 patients were stage IIIa and 3 patients were stage IIIb.

Group B; included 12 patients (10 males and 2 females) with a mean age of $48.67 \pm 10.10 ; 8$ patients had adenocarcinoma, 2 patients had squamous cell carcinoma and 2 patients had large cell carcinoma; 4 patients were stage IIIa and 8 patients were stage IIIb.

The mean volume of injected hot isotonic saline in group (A) was $366 \pm 165 \mathrm{ml}$ and mean volume of injected isotonic saline at room temperature in group (B) was $278.8 \pm 122 \mathrm{ml}$, and the number of sessions in group (A) was from 2 to 5 and from 1 to 5 in group (B). There was no statistically significant difference between group (A) and group (B) as regard injected volume and number of sessions $(\mathrm{P} \geq 0.05)$ (Table 2 ).

After 3 months, there was a statistically highly significant decrease in chest pain score in group (A) and group (B) versus before the start of treatment. After 6 months, there was a statistically highly significant decrease in chest pain score in group (A) only versus before the start of treatment. There was a statistically significant reduction in dyspnea score in group (A) after 3 months and after 6 months of treatment versus before the start of treatment.

Chest pain improved in $90 \%$ of patients in group (A) and in $25 \%$ in group (B) after 6 months and dyspnea improved in $45 \%$ of patients in group (A) and in $25 \%$ of patients in group (B). 
Table 2. Comparison between Chest Pain and Dyspnea Score before Treatment and after 3, 6 Months of Treatment.

\begin{tabular}{|c|c|c|c|}
\hline Symptom score & $\begin{array}{c}\text { Group A (n = 11) } \\
\text { Median (Min-Max) }\end{array}$ & $\begin{array}{c}\text { Group B (n = 12) } \\
\text { Median (Min-Max) }\end{array}$ & Test of significance \\
\hline Chest pain (before) & $3(1-4)$ & $3(0-3)$ & 0.357 \\
\hline Chest pain 3m & $2(0-3)$ & $2(0-3)$ & 0.974 \\
\hline Chest pain 6m & $2(0-3)$ & $2(0-3)$ & 0.516 \\
\hline Pre vs. 3m(P value) & $<0.001$ & 0.039 & \\
\hline Pre vs. 6m(P value) & 0.001 & 1.000 & 0.499 \\
\hline Dyspnea (before) & $3(1-3)$ & $2(1-3)$ & 0.563 \\
\hline Dyspnea 3m & $2(1-3)$ & $2(1-3)$ & 0.569 \\
\hline Dyspnea 6m & $2(1-3)$ & $2(1-3)$ & \\
\hline Pre vs. 3m(P value) & 0.006 & 0.339 & \\
\hline Pre vs. 6m(P value) & 0.038 & 1.000 & \\
\hline
\end{tabular}

There was no statistically significant decrease in cough and hemoptysis scores in both groups after 3 months and after 6 months of treatment versus before the start of treatment (Table 3).

There was a statistically significant increase in quality of life score (worsening of quality of life) in group (A) after 6 months of treatment versus before the start of treatment $(P=0.025)$. There was a statistically highly significant increase in quality of life score in group (B) after 3 months of treatment and after 6 months of treatment versus before the start of treatment $(\mathrm{P}<0.001$ and $\mathrm{P}$ $<0.001$ respectively)

As regard pulmonary functions, after 3 months, there were no statistically significant differences in FEV1 or FVC in both groups versus before treatment. After 6 months, there was statistically significant increase in FEV1 and FVC in group (A) versus before treatment $(\mathrm{P}=0.008,0.002$ respectively), but there were no statistically significant differences in FEV1 or FVC in group (B) versus before treatment $(\mathrm{P}=0.442,0.172$ respectively). There was no statistically significant increase in FEV1 in group (A) versus group (B) after 3 months of treatment $(\mathrm{P}=0.085)$ but there was a statistically significant increase in FEV1 in group (A) versus group (B) after 6 months of treatment $(\mathrm{P}=0.002)$. There was statistically significant increase in FVC in group (A) versus group (B) after 3 months of treatment $(\mathrm{P}=0.007)$. There was a statistically highly significant increase in FVC in group (A) versus group (B) after 6 months of treatment $(\mathrm{P}<0.001)$ (Table 4).

There was statistically significant difference between both groups after 3 and 6 months of treatment.

As regard the immediate complications of thermoablation, chest pain was recorded in 9 patients (81.8\%) in group (A) and 11 patients $(91.7 \%)$ in group (B) which easily controlled by analgesics. There was hemoptysis in one patient $(8.3 \%)$ of group (B). Skin burn was recorded in one patient $(9.1 \%)$ in group (A). 2 patients $(18.2 \%)$ of group (A) developed fever. Pneumothorax was recorded in one patient $(9.1 \%)$ in group (A) which resolved spontaneously with oxygen therapy. All of these complications were controlled and there was no procedure related mortality.

Histopathological examination of post injection tru cut biopsy revealed that 10 patients $(90.9 \%)$ of group (A) had coagulative necrosis post hot isotonic saline thermoablation while one patient
$(9.1 \%)$ revealed malignant cells in tissue biopsy. In group (B), 6 patients $(50 \%)$ had ischemic necrosis, 3 patients $(25 \%)$ had fibrosis and 3 patients $(25 \%)$ had malignant cells. There was statistically significant difference between both groups $(\mathrm{P}<0.001)$.

There were no down staging of all the studied cases after 6 months. The cost of saline injection for each patient was $20 \$ \mathrm{US}$.

Distant metastasis was reported in one patient (9.1\%) in group A and in 3 patients (25\%) of group (B) 6 months after treatment. There was no statistically significant difference of the tumor metastasis between the 2 groups $(\mathrm{P} \geq 0.05)$.

As regard patient survival at the end of the study, in group (A) 7 patients $(63.6 \%)$ were still alive, 4 patients $(36.4 \%)$ died; due to disease progression and in group (B) 6 patients (50\%) were still alive, 6 patients $(50 \%)$ died; (due to disease progression in 4 patients, massive pulmonary embolism in one patient and sudden death in one patient). The median survival of studied cases was 16 months (95\% confidence interval (CI) 11-21 months). The median survival of patients in group A was 17 months (95\% CI 12-23 months), meanwhile in group B the median survival was 13 months (95\% CI 9-17 months), however, the difference was not statistically significant) $(\mathrm{p}=0.3)$ as shown in Figure (1).

Figures 2, 3 and 4 shows selected cases presentation and their radiological responses.

\section{Discussion}

Patients with NSCLC are frequently surgically unfit because of coexistent chronic pulmonary disease or other co-morbidities. Therefore, they are frequently referred for chemoradiotherapy or palliative treatment [15].

Thermoablation is a minimally invasive treatment that is commonly used in endstage lung cancer, and which has shown promising results, the most widely used ablation modalities are radiofrequency ablation (RFA), microwave ablation, and cryoablation [16].

Thermoablation with hyperthermic saline or distilled water can be another option to ablate malignant tumors [17]. The use of percutaneous hot saline injection has been reported to give good 
Table 3. Comparison between Quality of Life Score before Treatment and after 3 and 6 months of Treatment.

\begin{tabular}{|c|c|c|c|}
\hline & $\begin{array}{c}\text { Group A (n = 11) } \\
\text { Median (Min-Max) }\end{array}$ & $\begin{array}{c}\text { Group B (n= 12) } \\
\text { Median (Min-Max) }\end{array}$ & $\begin{array}{c}\text { Test of } \\
\text { significance }\end{array}$ \\
\hline Quality of life pre & $1(0-2)$ & $1(0-2)$ & 0.830 \\
\hline Quality of life 3m & $1(0-2)$ & $2(1-3)$ & 0.004 \\
\hline Quality of life 6m & $1(0-3)$ & $3(0-4)$ & 0.002 \\
\hline Pre vs. 3m (P value) & 0.564 & $<0.001$ & \\
\hline Pre vs. 6m (P value) & 0.025 & $<0.001$ & \\
\hline
\end{tabular}

Table 4. Radiological Response in the Tumor Mass 3 and 6 months after Treatment Measured with CT Chest (Modified RECIST Criteria).

\begin{tabular}{|c|c|c|c|c|c|}
\hline & \multicolumn{2}{|c|}{$\begin{array}{c}\text { Group A } \\
(\mathrm{n}=11)\end{array}$} & \multicolumn{2}{|c|}{$\begin{array}{c}\text { Group B } \\
(\mathrm{n}=12)\end{array}$} & \multirow[t]{2}{*}{ Test of significance } \\
\hline & No & $\%$ & No & $\%$ & \\
\hline \multicolumn{5}{|l|}{ At 3 months } & \multirow{5}{*}{$\mathrm{P}<0.001$} \\
\hline - Complete response & 0 & $0 \%$ & 0 & $0 \%$ & \\
\hline - Partial response & 10 & $90.9 \%$ & 0 & $0 \%$ & \\
\hline - Stable & 0 & $0 \%$ & 9 & $75 \%$ & \\
\hline - Progression & 1 & $9.1 \%$ & 3 & $25 \%$ & \\
\hline \multicolumn{5}{|l|}{ At 6 months } & \multirow{5}{*}{$\mathrm{P}<0.001$} \\
\hline - Complete response & 0 & $0 \%$ & 0 & $0 \%$ & \\
\hline - Partial response & 8 & $72.7 \%$ & 0 & $0 \%$ & \\
\hline - Stable & 0 & $0 \%$ & 7 & $58.3 \%$ & \\
\hline - Progression & 3 & $27.3 \%$ & 5 & $41.7 \%$ & \\
\hline
\end{tabular}

Figure 1. Survival Probability of Studied Cases.

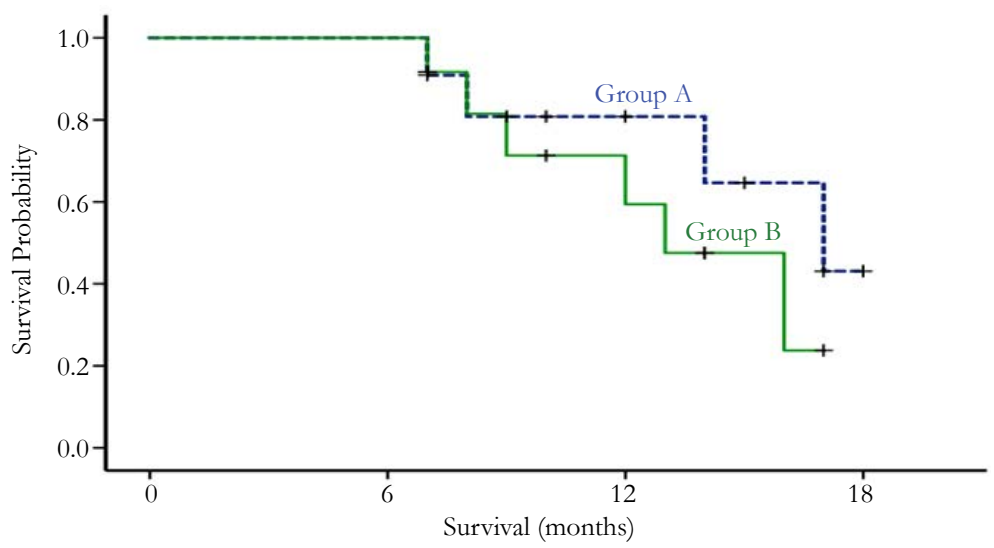

Figure 2. Female patient 32 years old, presented by cough (grade 1), dyspnea (grade 3), chest pain (grade 1), Karnofsky (80) and quality of life score (0), diagnosed as adenocarcinoma, tumor volume $350 \mathrm{cc}$, hot saline volume injected: $350 \mathrm{ml}$ in 4 sessions.

(A) preinjection picture, (B) partial response after 3 months, (C) partial response after 6 months.
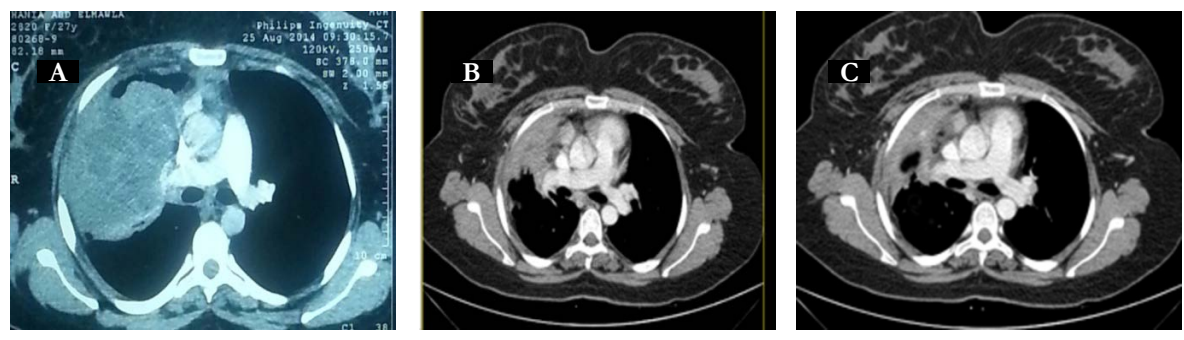
Figure 3. Male patient, 53 years old, presented by cough (grade 1), dyspnea (grade 3), chest pain (grade 3), Karnofsky (80) and quality of life score (0), diagnosed as squamous cell carcinoma, tumor volume $150 \mathrm{cc}$, hot saline volume injected: 150 $\mathrm{ml}$ in 2 sessions.

(A) preinjection picture, (B) partial response after 3 months, (C) partial response after 6 months.
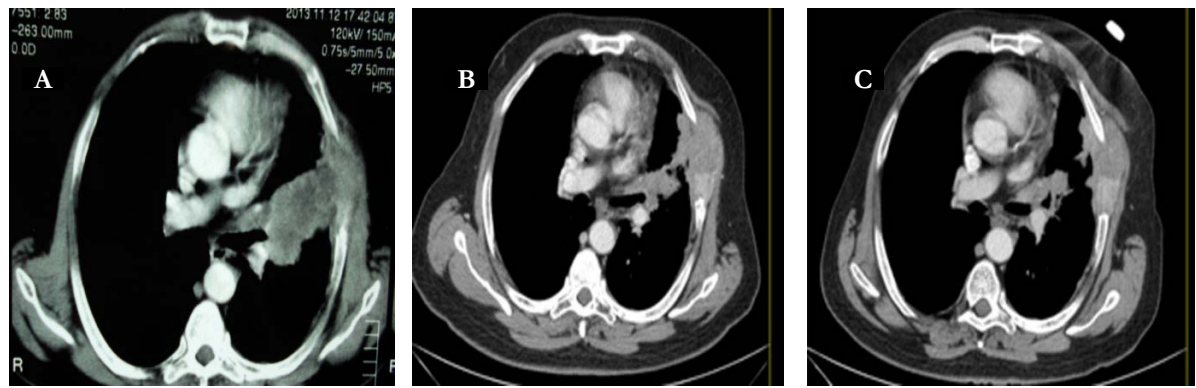

Figure 4. Male patient, 47 years old, presented by cough (grade 1), dyspnea (grade 3), chest pain (grade 1), Karnofsky (70) and quality of life score (1), diagnosed as adenocarcinoma, tumor volume $495 \mathrm{cc}$, hot saline volume injected: $495 \mathrm{ml}$ in 5 sessions.

(A) preinjection picture, (B) partial response after 3 months, (C) partial response after 6 months.
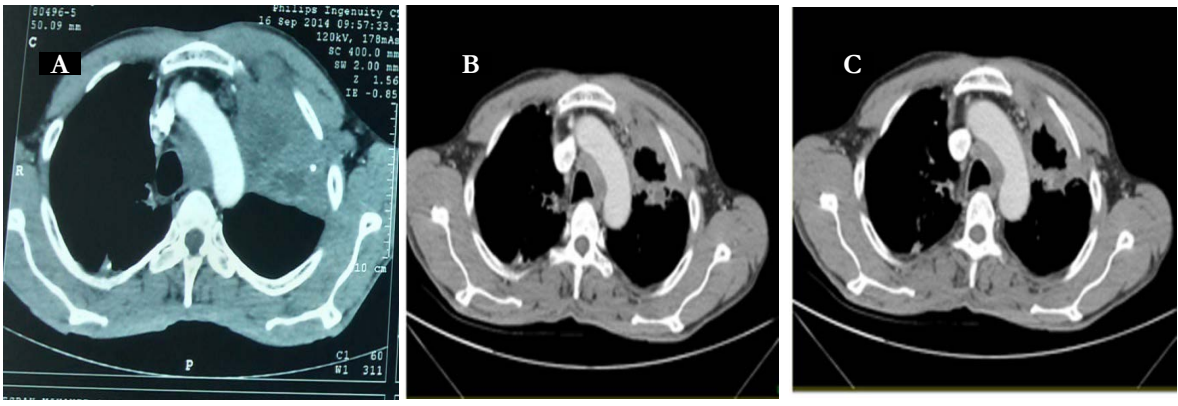

results especially in palliating relatively large masses; the tumor regression rate was $42 \%$ in patients with a median tumor size up to $7 \mathrm{~cm} \mathrm{[18].}$

To our knowledge, this is the first study to evaluate efficacy and safety of thermoablation by transthoracic injection of hot isotonic saline as palliative treatment of peripheral NSCLC to conventionally used protocol of chemotherapy. We compared our results with other thermoablative methods as radiofrequency and microwave ablation of peripheral NSCLC.

As regard the clinical response, a significant decrease of symptoms scores (chest pain and dyspnea) was reported in group (A) versus group (B) 3 and 6 months after treatment, chest pain improved in $90 \%$ of patients in group (A) and in $25 \%$ in group (B) after 6 months and dyspnea improved in $45 \%$ of patients in group (A) and in $25 \%$ of patients in group (B). This may be due to more reduction of tumor size in group (A) compared to group (B) and thermal affection of peripheral nerves or pain receptors. These results were comparable to Lee et al., [19] who reported that the response rates for the respiratory symptoms were $36 \%$ for chest pain and dyspnea. Our results were also comparable to Simon et al., [20] who reported symptoms improvement after 6 months as chest pain in $37 \%$ of patients. This supports that thermoablation by hot isotonic saline is comparable to radiofrequency in management of chest pain in peripheral lung cancer.

There was statistically a significant increase in quality of life score (worsening of quality of life) in group (A) after 6 months of treatment versus before the start of treatment $(\mathrm{P}=0.025)$. There was a statistically highly significant increase in quality of life score in group (B) after 3 months of treatment and after 6 months of treatment versus before the start of treatment. Our results were comparable to Belfiore et al., [6] who reported a significant improvement of quality of life 6 months after treatment by radiofrequency in tumor ablation. In our study, hot saline did not improve Karnofsky scale but prevent rapid deterioration in performance status and quality of life, so hot saline plus chemotherapy may be superior to chemotherapy alone.

As regard functional response, our results were near these results even better what supports that hot saline thermoablation is comparable to RFA as regard pulmonary functions as Ambrogi et al., [15] reported that FVC and FEV1 at 1 month from RFA minimally decreased, then, at after 3 months, they almost became matched with its value before RFA. In a study done by Ambrogi et al., [21] pulmonary function tests were done after 6 months of RFA in 27 patients. There was no significant decrease in FEV1, FEV1\% predicted, FVC, or FVC percentage predicted in any follow-up visits.

As regard radiological response after 3 months, in group (A) 10 patients showed partial response $(90.9 \%)$ and one patient showed progression (9.1\%) and in group (B), 9 patients showed no change $(75 \%)$ and 3 patients show progression (25\%). After 6 months, in group (A) 8 patients showed partial response $(72.7 \%)$ and 3 patients showed progression (27.3\%) and in group (B), 7 patients showed stable course $(58.3 \%)$ and 5 patients showed progression $(41.7 \%)$. And by comparison by another ablative therapy as radiofrequency, our results were comparable to Herrera et al., [22] who reported response rates after 6 months to RFA were as fol- 
lows: complete or partial response in 10 of 18 patients $(55 \%)$, stable disease in 6 of 18 patients $(33 \%)$, and tumor progression in 3 of 18 patients $(17 \%)$ with a mean diameter of $5.3 \mathrm{~cm}$. These findings were comparable to Lee et al., [19] who reported an overall complete necrosis rate of $38 \%$ at a mean follow-up of 12.5 months, they reported that tumor size measuring 3 to $5 \mathrm{~cm}$ were completely ablated in $38 \%$ of cases and lesions greater than $5 \mathrm{~cm}$ had only a $8 \%$ complete necrosis rate. In a study done by $\mathrm{Li}$ et al., [23] 31 patients $(63.3 \%)$ had a complete response, 12 patients $(24.5 \%)$ had a partial response, six patients $(12.2 \%)$ had stable disease, and no patients had progressive disease. In a study done by Chua et al., [24] of 148 patients treated, 66 patients (46\%) had a complete response, 38 patients $(26 \%)$ had a partial response, 57 patients $(39 \%)$ had stable disease and 23 patients $(16 \%)$ had progressive disease. Sun et al., [25] who used microwave ablation in 29 cases of peripheral lung cancer, complete response in $27 \%$, partial response in $48 \%$, stable in $13 \%$ and progression in $10 \%$ after microwave ablation. Our results were less than these studies as regard complete response, may be due to small size of tumors studied in these clinical trials in comparison to our study. As regard partial response, our results were better than their studies. Progression of tumor results in our study were comparable to their studies which gives us an idea that hot saline thermoablation was effective as RFA in slowing disease progression but we can't totally ablate large sized tumor using hot saline thermoablation.

As regard the immediate complications of thermoablation in the current study were less than that reported by Herrera et al., [22] who reported pleural effusion in 9 of 18 patients (50\%), pneumothorax in 7 patients $(53.8 \%)$, delayed pneumothorax in one patient $5 \%$, pneumonia in 4 patients $22 \%$, transient acute respiratory failure in one patient $5 \%$ and massive hemoptysis in one patient $5 \%$, Li et al., [23] who reported that there were no death related to the RFA procedure. The major complication was pneumothorax requiring chest tube placement, which occurred in $(11.9 \%)$. Minor complications $(19.4 \%)$, including self-limited minor pneumothorax, slight cough, a low-grade fever, and local pain at the puncture site, were well tolerated, Chua et al., [24] who reported that there was no treatment-related mortality. Sixty-six patients $(45 \%)$ had a pneumothorax, 16 patients $(11 \%)$ had a pleural effusion, $10 \mathrm{pa}-$ tients $(7 \%)$ had consolidation, 1 patient $(1 \%)$ developed bleeding and 12 patients (8\%) had pleuritic chest pain, Lee et al., [19] who reported pneumothorax $7 \%$, acute respiratory distress syndrome $3 \%$, small pneumothorax $23 \%$, subcutaneous emphysema $10 \%$, obstructive pneumonia $7 \%$, fever $7 \%$, pleural effusion $7 \%$ and hemoptysis $3 \%$. Sun et al., [25] who used microwave ablation in 29 cases of peripheral lung cancer, complications included 5, 2, and 15 cases of pneumothorax, pleural effusion, and fever, respectively. The difference between the current study and the above listed studies as regards the rate and type of complications following thermoablation may be due to the difference in the number of included patients in each study, difference in site or size of the tumor, less invasiveness of the needle in our study than RF probe and less immediate effect of hot saline in comparison to RF.

Histopathological examination of post 3 months tru cut biopsy was comparable to Yasui et al., [26] who reported that histopathological findings after 2 months were necrosis, fibrosis, or both, with no viable cells in 20 of $33(60.6 \%)$ ablation zones, and residual tumor cells in 13(39.4\%) ablation zones.

Distant metastasis was reported in one patient (9.1\%) in group
(A) and in 3 patients (25\%) of group (B) and 6 months after treatment. This was in contrast to Ambrogi et al., [15] who reported distant metastasis occurred in 39\% of patients at a mean followup period of 23.7 months. In the study done by Herrera et al., [22] in which 13 patients with pulmonary metastasis, 9 patients $(69 \%)$ had new metastases after RFA treatment. This could be explained in part by the large size of the lesions treated, with a mean size of $6.1 \mathrm{~cm}$, and also the difference in the length of the period of follow up or the number of cases.

As regard survival until the end of the study, in group (A) 7 patients $(63.6 \%)$ were still alive, 4 patients $(36.4 \%)$ died. In group (B) 6 patients $(50 \%)$ were still alive, 6 patients $(50 \%)$ died. The median survival of patients in group A was longer than in group B (17 months; 95\% CI 12-23 vs. 13 months; 95\% CI 9-17), however, the difference was not statistically significant) $(p=0.3)$. These results compare favorably to Ambrogi et al., [21] at the end of the study, 23 patients (40\%) were still alive. In a study by Lee et al., [19] the overall, 18 of 30 patients (60\%) died during follow-up (range, 1-21 months), while the remainder (40\%) are continuing to be followed up, with a present range of 11-24 months. The median survival of studied cases was 16 months (95\% (CI) 11-21 months). Our results were comparable to these reported by Herrera et al., [22], at a median follow-up of 6 months (range 1-10 months), death occurred in 7 of 18 patients (38\%). The difference between our results and these studies may be due to different follow up period, different disease stages, small number of cases and limited equipment (lack of experienced radiologist in MRI thermomemtry or sensitive electrodes).

There were no down staging of all the studied cases after 6 months. The cost of saline injection for each patient was 20 \$US. This cost was much less than the cost of other techniques like radiofrequency ablation $\$ 620.74$ [27].

There were some proportional limitations in our study as the need of better evaluation of tissue temperature by sensitive electrodes or MRI thermometry, repeated injection of larger volume exceeding tumor volume of hot isotonic saline may lead to better response, larger studies with large number of patients and hot saline thermoablation of small sized lung cancer are needed to be done for further evaluation of hot saline thermoablation.

\section{Conclusion}

Thermoablation using hot isotonic saline is an effective, safe and cheap palliative treatment for patients with inoperable peripheral NSCLC. Combination of thermoablation and chemotherapy may improve clinical symptoms as dyspnea and chest pain; also brake deterioration in quality of life.

\section{References}

[1]. Ferlay J, Steliarova-Foucher E, Lortet-Tieulent J, Rosso S, Comber H, et al., (2013) Cancer incidence and mortality patterns in Europe: estimates for 40 countries in 2012. Eur J Cancer . 49(6): 1374-1403.

[2]. Dupuy DE, DiPetrillo T, Gandhi S, Ready N, Donat W, et al., (2006) Radiofrequency Ablation Followed by Conventional Radiotherapy for Medically Inoperable Stage I Non-small Cell Lung Cancer. Chest. 129(3): 738-745.

[3]. Dupuy DE, Mayo-Smith WW, Abbott GF, DiPetrillo T (2002) Clinical Applications of Radio-Frequency Tumor Ablation in the Thorax. Radiographics. 22: S259-S269.

[4]. Araki Y, Hukano M, Urabe M, Inoue H, Bamba T, et al., (2004) Hepatocel- 
lular carcinoma treated by percutaneous hot saline injection. Oncol Rep. 12: 569-571.

[5]. Li GC, Mivechi NF, Weitzel G (1995) Heat shock proteins, thermotolerance, and their relevance to clinical hyperthermia. Int J Hyperthermia. 11(4): 459-488.

[6]. Belfiore G, Moggio G, Tedeschi E, Greco M, Cioffi R, et al., (2004) CTGuided Radiofrequency Ablation: A Potential Complementary Therapy for Patients with Unresectable Primary Lung Cancer-A Preliminary Report of 33 Patients. AJR Am J Roentqenol. 183(4): 1003-1011.

[7]. Van Kralingen KW, Van Kralingen-Heijboer AC, Zimmerman M, Postmus PE (1995) Management of haemoptysis in a third city hospital a retrospective study. Tuber Lung dis. 76(4): 344-8.

[8]. Melzack R (1987) The short-form McGill Pain Questionnaire. Pain. 30(2): 191-197.

[9]. Mahler DA, Wells CK (1988) Evaluation of clinical methods for rating dyspnea. 93(3): 580-586.

[10]. Gridelli C, Ardizzoni A, Chevalier T, Manegold C, Perrone F, et al., (2004) Treatment of advanced non small-cell lung cancer patients with ECOG performance status 2: results of a European Experts Panel. Ann Oncol. 15(3): 419-426.

[11]. Fernando HC, De Hoyos A, Landreneau RJ, Gilbert S, Gooding WE, et al., (2005) Radiofrequency ablation for the treatment of non-small cell lung cancer in marginal surgical candidates. J Thorac Cardiovasc Surg. 129(3): 639-644.

[12]. Goldstraw P, Crowley J, Chansky K, Giroux DJ, Groome PA, et al., (2007) The IASLC Lung Cancer Staging Project: proposals for the revision of the TNM stage groupings in the forthcoming 7 th edition of the TNM Classification of malignant tumors. J Thorac Oncol. 2(8): 706-714.

[13]. Winer-Muram HT, Jennings SG, Tarver RD, Aisen AM, Tann M, et al., (2002) Volumetric growth rate of stage I lung cancer prior to treatment: serial CT scanning. Radiology. 223(3): 798-805.

[14]. Cardenal F, Lopez-Cabrerizo MP, Anton A, Rosell R, Carrato A, et al., (1999) Randomized phase III study of gemcitabine-cisplatin versus etoposide-cisplatin in the treatment of locally advanced or metastatic non-smallcell lung cancer. J Clin Oncol. 17(1): 12-18.

[15]. Ambrogi MC, Lucchi M, Dini P, Mussi A, Melfi F, et al., (2006) Percutaneous radiofrequency ablation of lung tumours: results in the mid-term. Eur J Cardio-thoracic Surgery. 30(1): 177-183.

[16]. Dupuy DE, Shulman M (2010) Current status of thermal ablation treat- ments for lung malignancies. Semin Intervent Radiol. 27(3): 268-275.

[17]. Lau WY, Leung TW, Yu SC, Ho SK (2003) Percutaneous local ablative therapy for hepatocellular carcinoma: a review and look into the future. Ann Surg. 237(2): 171-179.

[18]. Yoon HK, Song HY, Sung KB, Chung YH, Lee S, et al., (1999) Percutaneous hot saline injection therapy: effectiveness in large hepatocellular carcinoma. J Vasc Interv Radiol. 10(4): 477-482.

[19]. Lee JM, Jin GY, Goldberg SN, Lee SY, Kim CS, et al., (2004) Percutaneous Radiofrequency Ablation for Inoperable Non-Small Cell Lung Cancer and Metastases: Preliminary Report. Radiology. 230(1): 125-134.

[20]. Simon CJ, Dupuy DE, DiPetrillo TA, Safron HP, Ng T, et al., (2007) Pulmonary radiofrequency ablation: long-term safety and efficacy in $153 \mathrm{pa}-$ tients. Radiology. 243(1): 268-275.

[21]. Ambrogi MC, Fanucchi O, Cioni R, Dini P, Davini F, et al., (2011) Longterm results of radiofrequency ablation treatment of stage I non-small cell lung cancer: a prospective intention-to-treat study. J Thorac Oncol. 6(12): 2044-2051.

[22]. Herrera LJ, Fernando HC, Perry Y, Gooding WE, Christie NA, et al., (2003) Radiofrequency ablation of pulmonary malignant tumors in nonsurgical candidates. J Thorac Cardiovasc Surg 125(4): 929-937.

[23]. Li X, Zhao M, Wang J, Fan W, Li w, et al., (2013) Percutaneous CT-guided radiofrequency ablation as supplemental therapy after systemic chemotherapy for selected advanced non-small cell lung cancers. AJR Am J Roentqenol. 201(6): 1362-1367.

[24]. Chua TC, Sarkar A, Saxena A, Glenn D, Zhao J, et al., (2010) Long-term outcome of image-guided percutaneous radiofrequency ablation of lung metastases: an open-labeled prospective trial of 148 patients. Ann Oncol. 21(10): 2017-2022.

[25]. Sun YH, Song PY, Guo Y, Sheng LJ (2015) Computed tomography-guided percutaneous microwave ablation therapy for lung cancer. Genet Mol Res. 14(2): 4858-4864

[26]. Yasui K, Kanazawa S, Sano Y, Fujiwara T, Kagawa S, et al., (2004) Thoracic tumors treated with CT-guided radiofrequency ablation: initial experience. Radiology . 231(3): 850-857.

[27]. Alexander ES, Machan JT, Ng T, Breen LD, Dipetrillo TA, et al., (2013) Cost and effectiveness of radiofrequency ablation versus limited surgical resection for stage i non-small-cell lung cancer in elderly patients: Is less more? J Vasc Interv Radiol. 24 (4): 476-482 